\title{
GENETTE E O FANTÁSTICO
}

Wandeir Araújo Silva

Liane Schneider

\section{RESUMO}

O texto a seguir pretende analisar como importantes tópicos discutidos pelo teórico francês Gérard Genette em $O$ discurso da narrativa se comportam perante as teorias da narrativa fantástica, especialmente a apresentada por Tzvetan Todorov em Introdução à literatura fantástica. De acordo com nosso ponto de vista, podemos perceber que certos procedimentos apontados por Genette são úteis na construção do fantástico, tais como a paralipse e demais recursos relativos ao modo de narrar. Utilizaremos exemplos da literatura fantástica brasileira a fins de confirmação de nossas especulações.

\section{PALAVRAS-CHAVE:}

Gérard Genette; Tzvetan Todorov; teoria do fantástico; conto; Literatura Fantástica.

\section{Todorov e o Fantástico}

Temas envolvendo o sobrenatural, o insólito, aquilo que não se pode explicar, estão presentes em nossa história desde tempos imemoriais. Entretanto, o século XVIII trouxe o lluminismo, a era das luzes e do pensamento racional, criando as principais tendências que mais tarde acabariam por atingir a forma de se ver a literatura, culminando na escola realista. A predominância desta forma de ver o mundo acabou por incomodar certa parte dos escritores e criou um movimento no sentido contrário, fazendo com que o sobrenatural ganhasse mais força dentro da literatura. O auge do movimento se deu com a força do romance gótico de Horace Walpole e Ann Radcliffe. Novos escritores foram surgindo, mas ainda era muito grande a dificuldade em se definir o que seria o fantástico.

Entre confusões e diversas interpretações que perduram até nossos dias, 0 fantástico conseguiu certa sistematização apenas no século $X X$, a partir dos estudos de Todorov. O pensador búlgaro-francês trouxe uma rica análise da narrativa fantástica feita nos séculos XVIII e XIX, formando uma base muito difícil de ser ignorada, pois é ponto de partida de todo bom trabalho sobre este gênero narrativo. Isso se deve ao fato de sua teoria do fantástico ser bastante consistente, exibindo constantes inegáveis da construção do fantástico. Nisto, Introdução à literatura fantástica apresenta interessantes pontos a se discutir. 


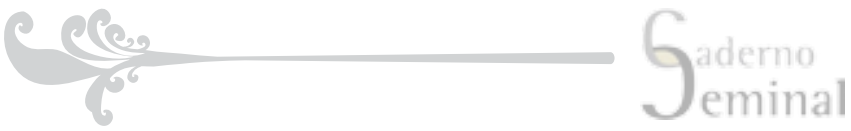

O primeiro deles diz respeito à necessidade de um evento insólito, isto é, algum elemento ou acontecimento apresentado que fira a lógica interna da diegese, algo que destoa e desafia a lógica vigente. Com a irrupção desse evento, surgirá a situação de dúvida, que propiciará, tanto aos personagens quanto ao leitor, a sensação de hesitação, perplexidade e - não raro - de medo. Essa sensação perdurará por toda a narrativa, sem se desfazer ao final, o que faz com que o desfecho seja também inexplicável. Segundo Todorov apresentar uma explicação plausível nos afastaria do fantástico, nos levando a um de seus gêneros vizinhos. Se a explicação for lógica, real, estaremos diante do estranho, enquanto se, por outro lado, explicássemos o problema com uma justificativa sobrenatural, adentraríamos o território do maravilhoso. Baseandose na percepção de seus vizinhos, o estudioso conclui que "O fantástico ocorre nesta incerteza (...). O fantástico é a hesitação experimentada por um ser que só conhece as leis naturais, face a um acontecimento aparentemente sobrenatural" (TODOROV, 2010, p. 31). Tendo sido essa hesitação o segundo ponto a considerar na construção do fantástico, chegamos ao terceiro, em que Todorov sugere que haja um pacto entre o leitor e a obra, que o impossibilita de vê-la como poesia ou alegoria. Isto significa que uma linguagem poética, metafórica, é insuficiente na instauração do fantástico, pois ela está mais para uma estilização da realidade, que para uma ruptura desta. Por outro lado, a alegoria faria com que o leitor captasse algum sentido diante dos fatos narrados, o que desfaria a sensação de perplexidade causada pela inexplicabilidade dos eventos. Caso sejam conservadas estas três premissas, o fantástico estaria garantido à narrativa.

Percebamos que alguns destes pontos são questionáveis, fato que faz com que novos teóricos venham se dedicando a rever, contradizer ou complementar a teoria todoroviana, mas não buscaremos este problema neste estudo. Foquemonos então às correlações entre Todorov e Genette.

\section{Genette e o modo de narrar}

Os estudos de Gérard Genette trazem observações pertinentes acerca da composição dos narradores, sendo expostas de maneira muito ampla e detalhada. Vejamos então algumas importantes definições.

Observando as possíveis distâncias que aquele que narra pode assumir em relação ao acontecimento narrado, o autor já estabelece dois tipos básicos de narrativa. É posto então que a narrativa de acontecimentos é aquela em que o narrador assume maior distância do ocorrido, o que fica claro ao leitor de acordo com a condução da narração.

A "imitação" homérica de que Platão nos propõe uma tradução em "narrativa pura" não comporta mais que um breve segmento dialogado. Ei-lo, primeiro 
na sua versão original: "diz ele, e o velho, à sua voz, ganha medo e obedece. Vai-se embora em silêncio, ao longo do areal onde rola o mar, e, quando, fica só instantaneamente o velho implora o senhor Apolo, filho de Leto dos belos cabelos". E agora na reescrita platônica: "O velho, ouvindo tais ameaças, teve medo e foi-se embora sem dizer nada; mas, uma vez fora do campo, dirigiu a Apolo instantes orações" (GENETTE, 1995, p.163).

A citação acima mostra a comparação que Genette faz entre dois trechos da narrativa homérica, sendo o segundo uma tradução feita por Platão. O objetivo é mostrar que, amparado ao que diz o filósofo sobre a mimese, uma narrativa pode se tornar mais pura, isto é, mais próxima do real, a partir da exclusão de termos redundantes da narrativa fazendo com que ela se mostre mais. $O$ efeito acaba criando um paradoxo: menos se detalha, porém mais se apreende com relação à realidade, ou seja, que se constitui de cenas e, consequentemente, é mais mimética (Cf. GENETTE, 1995, p. 165).

Assim, o autor destaca, sempre se baseando na mimese grega, a existência de uma forma narrativa oposta, tida como a narrativa de falas. Elas se diferem das narrativas de acontecimentos por serem construídas essencialmente das falas, seja do narrador ou das personagens, evitando uma imitação. À primeira vista sente-se certa confusão nessas observações, mas elas se tornam mais claras a partir das tipologias empregadas por Genette ao ver os diferentes tipos de falas. A primeira diz respeito ao discurso narrativizado ou contado, que equivale ao que comumente temos como discurso indireto. Já a segunda forma de discurso, a forma transposta, também é baseada no discurso indireto, mas se mostra menos distante do acontecimento. Ao observamos os trechos de Em busca do tempo perdido ${ }^{1}$ comentados por Genette, percebemos melhor a diferença entre estas duas primeiras tipologias. Na primeira: "Informei a minha mãe da minha decisão de desposar Albertine" (PROUST, apud. GENETTE, 1995, p. 169). Já na forma transposta: Disse a minha mãe que era absolutamente necessário para mim desposar Albertine" (PROUST, apud. GENETTE, 1995, p. 169). Por fim, ainda temos o discurso relatado, ou seja aquele em que a palavra é cedida literalmente ao personagem, o que o aproxima do modo dramático, facilmente reconhecido como o discurso direto. Mediante estas classificações torna-se mais fácil perceber como a distância pode ser variável. Umas "mostram" mais do que "contam", mas todas compõem um grande leque de opções ao escritor.

\section{Focalização}

Além da distância, Genette também discursa sobre a perspectiva, isto é, do ponto de vista estabelecido pela narração. $O$ autor sugere alguns tipos de divisão entre as possíveis perspectivas a adotar. Comentemos um pouco sobre estas.

1 Título do clássico de Marcel Proust, que é usado como base para a apresentação das proposições de Genette quanto ao modo de narrar. 
A focalização-zero nos parece um tanto difícil de compreender, talvez por Genette pouco se apegar a ela em seu estudo. A ideia que temos desse tipo de focalização é de uma "omnisciência do romancista clássico" (GENETTE, 1995, p. 206), ou seja, a forma de narrar comum do romance do século XIX, em que o narrador sabe de tudo, porém pouco se aproxima dos fatos, fazendo com que eles se apresentem da forma mais neutra possível ${ }^{2}$. Em seguida, somos apresentados à focalização interna, que como o próprio nome propõe, visa expor as características intrínsecas de um personagem. Esse tipo de focalização pode ser fixa (quando apenas um personagem é o focalizado), variável (quando se alterna o foco narrativo entre dois personagens) e múltipla (vários personagens sendo focalizados). O terceiro tipo de focalização é a externa, que se difere da interna por não permitir que se tenha acesso à consciência do personagem em foco ${ }^{3}$. Entender como se comportam estas diferentes perspectivas se torna mais fácil quando pensamos não somente na literatura, mas também no cinema. Lembremo-nos de como a câmera consegue adotar diferentes pontos de vista para causar o impacto desejado no espectador e não perceberemos muita diferença com o que acontece nos textos literários.

Além do que vimos, é interessante ressaltar o que fala Genette (1995, p. 189190) ao concluir sua exposição sobre os tipos de focalização:

A fórmula de focalização nem sempre se aplica ao conjunto de uma obra, portanto, mas antes a um segmento narrativo determinado, que pode ser muitíssimo breve. Por outro lado, a distinção entre os diferentes pontos de vista nem sempre é tão nítida quanto a simples consideração dos tipos puros poderia fazer supor. Uma focalização externa em relação a uma personagem pode, por vezes, igualmente bem deixar-se definir como uma focalização interna sobre outro.

Acima, Genette chama a atenção, de forma bastante inteligente, para que não tenhamos nenhuma das focalizações descritas por ele como absolutas, determinantes ou estanques na narrativa, fato que atribui mais flexibilidade à teoria e nos abre os olhos para que analisemos minuciosamente cada cena apresentada por determinada obra.

A partir das mudanças de focalização ao longo da narrativa, é natural que alguns elementos, antes pouco ou não visíveis, se tornem mais evidentes, bem como o inverso, quando coisas que estavam em nossa vista são ocultadas. Isso faz com que a quantidade de informação oferecida possa ser regulada, geralmente para dar mais dinamismo à narração ou gerar expectativa em

2 Vale a pena ressaltar que a definição dada por Genette é bastante vaga ou ambígua. Quando este se refere ao romancista clássico, por exemplo, não temos com exatidão o que ele quer dizer com esse termo. Sendo assim, a definição apresentada neste artigo passa também pela nossa interpretação do termo, o que talvez difira da definição de Genette. Outro questionamento interessante a se fazer sobre a focalização-zero diz respeito a sua posição de neutralidade. Como acreditamos ser impossível que se adote uma perspectiva neutra, optamos por expor a focalização-zero como uma forma narrativa que busca a neutralidade, mas nunca a alcançando por completo.

3 Percebamos que a focalização-zero também pode ser confundida com a focalização externa. Acreditamos que a principal diferença entre elas se dá no fato de a focalização-zero ser de caráter mais descritivo, enquanto a externa, embora não nos permita conhecer o interior de um personagem, ainda pode ater-se a ele mais efetivamente. 


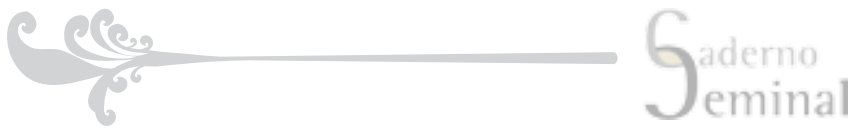

quem lê. Assim, o autor nos apresenta dois novos conceitos: o de paralipse e o de paralepse. O primeiro trata de omissão lateral, isto é, uma subtração ou escassez de informação ${ }^{4}$ cedida ao leitor. Já a paralepse faz com que a alteração de focalização ceda mais informação do que o possível. Novamente é possível perceber melhor como essas mudanças se comportam quando nos lembramos do cinema; em um filme de suspense, por exemplo, tende-se sempre à paralipse, para que o espectador não tenha certeza do que ocorre, mantendo a expectativa quanto ao desenrolar da trama.

Expostos os principais conceitos acerca do modo narrativo da teoria de Gérard Genette, vejamos como estes se comportam diante da teoria do fantástico todoroviano.

\section{O fantástico e a focalização}

O conto "Lua crescente em Amsterdã", de Lygia Fagundes Telles, tem como protagonista um casal que discute sentado em um banco de jardim em Amsterdã. Ambos estão fora do lugar onde vivem e, ao chegarem à capital holandesa, sentem imenso desconforto. Essa angústia se faz mais evidente na moça, Ana, que chora insistentemente, querendo voltar para casa. A cena inicial nos mostra o casal sentado no banco, diante de uma criança que porta uma fatia de bolo. Ana sente fome e pede um pedaço do bolo, mas a garotinha foge assustada:

— Vai me dar um pedaço desse bolo? - pediu a jovem estendendo a mão.

- Me dá um pedaço, hem, menininha?

- Ela não entende - ele disse.

A jovem levou a mão até a boca.

- Comer, comer! Estou com fome - insistiu na mímica que se acelerou, exasperada. - Quero comer!

— Aqui é a Holanda, querida. Ninguém entende. (TELLES, 1981, p. 59).

Irritados com o local onde mal podem se comunicar com outras pessoas, o casal começa uma longa discussão, que proporciona um longo devaneio. Nisto, Ana pensa que seria menor o seu sofrimento caso pudesse, de alguma forma, nascer ou tornar-se algum outro ser:

Ela levantou as mãos e passou as pontas dos dedos nos cabelos. Na boca.

- E agora? O que acontece quando não se tem mais nada com o amor?

Quase ele levou de novo a mão no bolso para pegar o cigarro, onde fumara o último?

- Sopra o vento e a gente vira outra coisa.

- Que coisa?

- Sei lá. Não quero é voltar a ser gente, eu teria que conviver com as pessoas e as pessoas - ele murmurou. - Queria ser um passarinho, vi um dia um passarinho bem de perto e achei que devia ser simples a vida de

$4 \quad$ Não confundamos a paralipse com a elipse. Grosso modo, a elipse é uma figura de linguagem que permite a extirpação de termos redundantes de uma sentença a fim de torna-la mais objetiva, sem que haja qualquer prejuízo a sua compreensão. Por outro lado, a paralipse omite elementos que são essenciais à trama - o que faz com que o leitor sinta imediatamente a ausência deles. Evidentemente, a paralipse pode usufruir de elipses (no discurso de um personagem, por exemplo) para produzir o efeito desejado. 
um passarinho de penas azuis, os olhinhos lustrosos. Acho que queria ser aquele passarinho.

- Nunca me teria como companheira, nunca. Gosto de mel, acho que quero ser borboleta. É fácil a vida de borboleta?

- E curta. (TELLES, 1981, p. 64).

Ao término da narrativa, o evento fantástico acontece, mas de forma sugerida, bastante sutil: ambos parecem ter sido transformados nos animais com que devaneavam. A narrativa se apresenta como um bom exemplo para que observemos uma a uma as nuances e premissas do fantástico sob a ótica de Todorov. O acontecimento insólito está presente. Entretanto, não há hesitação sequer por parte dos personagens; o questionamento e hesitação se projeta ao leitor de uma outra forma, o que pode nos fazer declarar que "Lua crescente em Amsterdã" "(...) É fantástico tão-somente pela incerteza do acontecimento inusitado, possibilitado pelas interferências dos índices discursivos e pela sua inexplicabilidade" (SAMPAIO, 2009, p. 82). Uma vez que não temos a participação efetiva das personagens na construção do fantástico, seria possível perceber o que as substituiu? Prestemos atenção à cena final do conto:

O vento soprou tão forte que a menina loura teve que parar porque o avental Ihe tapou a cara. Segurou o avental, arrumou a fatia de bolo dentro do guardanapo e olhou em redor. Aproximou-se do banco vazio. Procurou por entre as árvores, voltou até o banco e alongou o olhar meio desapontado pela alameda também deserta. Ficou esfregando as solas dos sapatos na areia fina. Guardou o bolo no bolso e agachou-se para ver o passarinho de penas azuis bicando com disciplinada voracidade a borboleta que procurava se esconder debaixo do banco de pedra. (TELLES, 1981, p. 64).

Ao longo da narrativa, temos uma focalização centrada apenas nos dois protagonistas, podendo ser vista como uma focalização interna e variável (Cf. GENETTE, 1995, p. 187) a maior parte do tempo, uma vez que temos acesso às emoções e falas de ambos com certa alternância característica dos diálogos. Usando nossa já familiar comparação com o cinema, a situação seria facilmente visualizada como um shot/reaction-shot somado à câmera subjetiva. Conforme explicita Xavier (2008, p. 34),

A câmera é dita subjetiva quando ela assume o ponto de vista de uma das personagens, observando os acontecimentos de sua posição, e, digamos, com os seus olhos. O shot/reaction-shot corresponde à situação em que o novo plano explicita o efeito (em geral psicológico) dos acontecimentos mostrados anteriormente no comportamento de alguma personagem.

A construção cinematográfica da narrativa não para por aí. Próximo ao desfecho, a focalização sofre uma mudança drástica, pois é deslocada do casal para a garotinha que aparecera com o bolo no início da história. Uma vez focando-se nela, deixamos de ver o momento em que se realizaria a metamorfose do casal. Toda essa situação nos é ocultada através da paralipse que se forma com o 


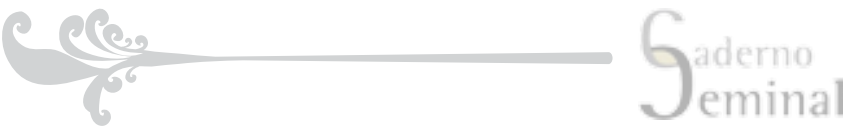

deslocamento do foco, que, por sua vez, sustenta a hesitação necessária à concepção do fantástico. Em outras palavras, a cena da metamorfose é cortada da narrativa para que fiquemos apenas com a reação da menina. Contudo, também a menina não apresenta nenhuma reação específica, pois também ela teve sua visão obstruída em relação à metamorfose, por causa do vento que lhe atira no rosto o avental. O resultado é uma situação de metamorfose apenas sugerida, impedindo que o leitor assuma uma explicação (tanto natural quanto sobrenatural) ao acontecido. Todo este artifício também serve para que essa principal característica do fantástico, a de hesitação frente a um acontecimento que desafia a lógica vigente, não precise ser feita a partir de uma narração em primeira pessoa ou, nas palavras de Todorov (2010, p. 94), de um narrador representado:

O narrador representado convém ao fantástico, pois facilita a necessária identificação do leitor com as personagens. O discurso deste narrador possui um estatuto ambíguo e os autores o tem explorado diferentemente enfatizando um ou outro de seus aspectos: quando concerne ao narrador, o discurso se acha aquém da prova de verdade; quando à personagem, deve se submeter à prova.

Destarte, vemos que há outras possibilidades de realização do fantástico além das expostas por Todorov, conforme observamos a partir dos artifícios tangentes à teoria de Genette.

Não só Telles parece ter feito uso destes artifícios. Também é possível encontrar uma estruturação de cena muito bem feita em "O terceiro reinado", conto da escritora contemporânea Georgette Silen. No texto supracitado, conhecemos a cidade do Rio de Janeiro vista de uma forma bastante peculiar. Ambientando-se no século XIX, o conto cria um cenário hipotético, em que a monarquia resiste bravamente e conduz o Brasil a uma prosperidade invejada por muitas potências europeias, graças aos investimentos tecnológicos do governo Imperatriz Isabel, filha de D. Pedro II. A tecnologia à base do vapor cria aparatos que melhoram a vida de toda a população - fato que irrita os republicanos, que perdem cada vez mais força. Vejamos um exemplo:

Antigas leis, como a Ventre Livre e Sexagenária, foram revogadas. Escravos idosos demais para se sustentarem em pé eram recondicionados nos laboratórios do império, tendo partes dos corpos decrépitos substituídas por próteses, tornando-se a primeira geração de bioescravos, com peçasmotores funcionando à base de combustíveis gasosos, numa pesquisa e aplicação pioneira em todo o mundo (SILEN, 2011, p. 74).

Composto todo este ambiente bastante característico do gênero steampunk ${ }^{5}$, chegamos ao principal evento do conto: a apresentação da Imperatriz Isabel,

$5 \quad$ Corresponde a uma das vertentes da ficção científica ou especulativa, em que se recria certo período histórico (em geral o final do século XIX, que corresponde à Era Vitoriana na Inglaterra) amparando-se às tecnologias da época como o vapor. 
locomotiva de luxo que é produto de um projeto ambicioso, visando a travessia do Rio de Janeiro a Itabuna, Bahia, em duas horas. A própria Imperatriz do Brasil de Santa Cruz estaria a bordo na viagem inaugural. Eis que, pouco antes da partida, o maquinista do veículo, Francisco Zander, recebe a visita de Moncorvo Filho, reitor de um importante instituto de pesquisa. O reitor especula se não seria melhor se a viagem fosse feita com os quatro motores ligados, em vez de dois, como se previa. Segundo nos é explicado, isso tornaria a viagem surpreendentemente mais curta - com apenas uma hora. A persuasão tem clara motivação política, tanto para expor o sucesso da Monarquia aos republicanos quanto aos demais países na corrida pelo desenvolvimento. Depois de muita conversa, Zander acaba aceitando a recomendação de Moncorvo, o que conduzirá o leitor ao surpreendente desfecho. Chegando a Itabuna, o trem surpreende ao abrir suas portas e mostrar quem não havia absolutamente ninguém mais em seu interior.

Na cabine de comando, encontraram as xícaras e o café preto ainda quente
(...) Mas nenhum sinal de Francisco Zander, da tripulação ou passageiros. O
silêncio soprava mistérios que nunca seriam revelados. O chefe da estação
mirou o painel de comando (...) conferiu os contadores de velocidade. Os pelos
de sua nuca se arrepiaram. Os números não podiam ser reais! Bateu com
o polegar e o indicador sobre o mostrador, mas ele não se moveu. Conferiu
os demais instrumentos, os registros de rota, qualquer dado de navegação
da locomotiva. Todos se detinham na mesma marca, pontuada em vermelho.
Uma velocidade que nenhum homem jamais pensou em alcançar (SILEN,
2011, p. 82).

Após a constatação de que algo inexplicável acontecera, o chefe da estação de Itabuna pouco demonstra perplexidade, traz apenas a coroa da Imperatriz, então desaparecida, em suas mãos, apenas pensando na nova realidade que se apresentaria dali em diante. De maneira similar ao que vimos no conto de Lygia Fagundes Telles, aqui também pouco há de perplexidade por parte daqueles que presenciaram a chegada da locomotiva. Talvez a maior demonstração de susto seja quando o chefe da estação se depara com o velocímetro do trem. No mais, o público do lado de fora não tem acesso a nada mais, ficando a mercê apenas da volta do chefe da estação de posse da coroa real. Analisemos como se comporta então a focalização na concepção desse desfecho.

Ao longo de "O terceiro reinado", diferente do que acontece em "Lua crescente em Amsterdã", temos cenas bastante amplas, em sua maioria, que podem ser vistas como uma focalização-zero, uma vez que se limitam a descrever o espaço narrativo, sem muito se ater a eventos mais específicos, em que se poderia adotar a focalização externa como fonte. A situação só muda às vésperas da partida do trem, quando temos uma focalização interna e variável no diálogo em que Moncorvo persuade Zander a ativar os quatro motores durante a viagem. Percebamos que durante o desenrolar das ações o foco é o trem e 


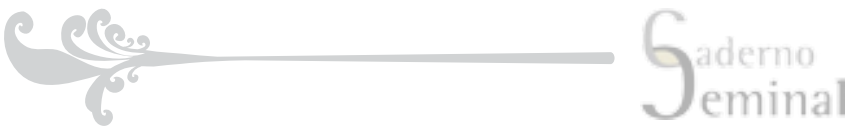

as pessoas que estão em seu interior. Curiosamente, tal como aconteceram no conto de Telles, a focalização se afasta do local onde ocorrerá o evento fantástico, fazendo com que tenhamos acesso apenas a seus resultados - ou seja, novamente o fantástico é construído por meio de uma paralipse obtida com a mudança brusca de focalização. Mesmo quando o chefe da estação adentra a locomotiva, ainda não temos certeza do que ocorrera, fica apenas a sugestão de que os tripulantes foram deslocados no espaço-tempo devido à alta velocidade. Também nesta narrativa o fantástico não foi construído a partir de um narrador representado, o que fica claro ao observarmos as diferentes facetas da focalização ao alongo da narrativa. Outro questionamento que podemos levantar diz respeito ao mundo onde ocorre a narrativa de "O terceiro reinado". Ao contrário do primeiro conto comentado, estamos diante de uma versão hipotética do mundo real, não estamos exatamente no mundo real. Tudo isso pode também nos fazer questionar as principais bases do fantástico, já que aqui temos uma quebra da lógica vigente, mas não o mundo real como o conhecemos; temos hesitação e inexplicabilidade projetadas ao leitor, mas o mundo da narrativa já não é mais o nosso. Enfim, os dois contos acima servem para mostrar que algumas assertivas sobre o fantástico não se portam como absolutas, pois novos procedimentos criam novas constantes que não foram previstas pela teoria de Todorov.

\section{Conclusão}

Mediante as exposições das teorias de Gérard Genette e Tzvetan Todorov, e com a ajuda dos exemplos que analisamos, podemos notar que os principais tópicos relacionados à teoria de Genette são bastante pertinentes quando aplicados ao fantástico.

Em um primeiro momento, essas ponderações colaboram com os principais postulados da teoria de Todorov. Chamamos atenção, inclusive, ao brilhante papel da paralipse na construção do fantástico. Podemos observar que se, segundo Todorov, devemos manter no leitor a incerteza e a incapacidade de explicar os fatos que lê, seja de modo natural ou sobrenatural, a omissão de dados essenciais para a compreensão total é quase imperativa - pensamento que induziria o escritor a fazer uso de paralipses, conforme pudemos perceber à leitura de "Lua crescente em Amsterdã" e "O terceiro reinado". Resumindo: convém ao fantástico o uso de um discurso paralíptico.

Por outro lado, a imensa variedade de distâncias que pode ser conseguida dentro de uma mesma narrativa, conforme é explicitado ao estudarmos os diversos tipos de focalização, ajuda a mostrar que certas afirmações da teoria de Todorov não seriam tão importantes - como no caso da narração em primeira pessoa. Ambas as narrativas usadas como exemplo são em terceira pessoa, mas conseguem manter o caráter inverossímil do evento fantástico a partir de 


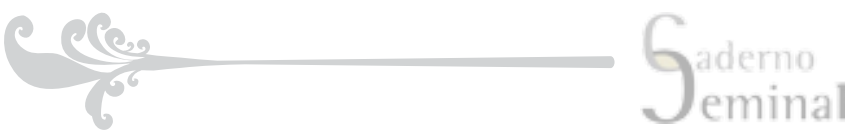

outros recursos. Tais recursos ganham muito com a variação de focalização que pode, além de chamar a percepção do leitor para a composição espacial da narrativa, impedir-Ihe ou permitir-Ihe de ter acesso a determinadas informações que seriam de suma importância. Evidente que a variação de distância e focalização não é o único tipo de procedimento que pode proporcionar isso, mas fica bem claro, a partir dos exemplos comentados, o forte auxílio que este recurso pode prestar ao escritor que deseja criar novas possibilidades de criação do fantástico. Destarte, temos em mãos uma excelente ferramenta para subverter as principais tendências da narrativa fantástica, contribuindo para sua originalidade e difusão, bem como fazendo com que os estudos teóricos sigam desbravando novas vertentes do gênero ou novas possibilidades de escrita.

\section{GENETTE AND THE FANTASTIC}

\section{ABSTRACT}

The following text intends to analyze how important topics discussed by the French theorist Gérard Genette in his Narrative discourse: an essay in method can be used with the theories of the fantastic literature, especially the Tzvetan Todorov's theory, presented in The Fantastic: a structural approach to a literary genre. According to our point of view, we can notice that some aesthetical procedures appointed by Genette are very useful to create the fantastic, such as the paralipsis and another procedures related to the narrative mood. We will present examples found in Brazilian fantastic literature in order to confirm our speculations.

\section{KEY-WORDS:}

Gérard Genette, Tzvetan Todorov, Theory of the fantastic, short-story, fantastic literature.

\section{REFERÊNCIAS}

GENETTE, Gérard. Discurso da Narrativa. 3ª ed. Lisboa: Veja, 1995 (coleção Veja Universidade).

SAMPAIO, Aíla. Os fantásticos mistérios de Lygia. Fortaleza: Expressão Gráfica Editora, 2009.

SILEN, Georgette. O terceiro reinado. In: RUIZ, Tatiana (org.). Steampink. Belo Horizonte: Estronho, 2011, p. 72-83. 
TELLES, Lygia Fagundes. Lua crescente em Amsterdã. Mistérios. Rio de Janeiro: Nova Fronteira, 1981, p. 57-64.

TODOROV, Tzvetan. Introdução à literatura fantástica. São Paulo, Perspectiva, 2010.

XAVIER, Ismail. A decupagem clássica. O discurso cinematográfico: a opacidade e a transparência. 4ª ed. São Paulo: Paz e Terra, 2008. 